\title{
A simple method for measuring brain asymmetry in children: Application to autism
}

\author{
R. A. Wittling ANd E. SCHWEiger \\ FinTec GmbH, Neunkirchen, Germany \\ and University of Trier, Trier, Germany \\ L. Rizhova ANd E. A. Vershinina \\ Autisme Centre Vestsjelland, Slagelse, Denmark \\ and Pavlov Institute of Physiology RAS, St. Petersburg, Russia \\ AND \\ L. B. STARUP \\ Autisme Centre Vestsjelland, Slagelse, Denmark
}

\begin{abstract}
A device for measuring signal transfer within and between hemispheres has been developed at the Center for Neuropsychological Research at the University of Trier, Germany. It contains two identical panels allowing both tactile stimulation and motor response with buttons for the fingers of each hand. The buttons have two functions. They can exert a slight tactile stimulation to a finger, and they can be pressed down by the finger to provide a motor response to the tactile stimulation allowing measuring the response time. The device was used for measuring brain asymmetry in tactile processing autistic children. The participants were given a finger tapping test followed by the procedures with unilateral and bilateral processing of tactile stimulation. All participants responded positively to the test procedure and accepted it as a kind of game. The results indicated that brains were more asymmetrical in autistic children than in controls: The right hemisphere functioned quicker than the left hemisphere.
\end{abstract}

Measuring behavior in people with mental handicaps and psychic illnesses is important for both diagnostics and the investigation of pathological processes. Questioning and observation - the prevalent methods now in diagnostics of mental pathological conditions-take a lot of time, and the results are greatly subjective. The availability of standardized tools is limited, observations are unstructured, and the procedure can vary depending on theoretical orientation and experience of the psychologist (Akshoomoff, Corsello, \& Schmidt, 2006). Technical methods have comparative advantages, such as the possibility to direct measuring brain functions, high effectiveness and preciseness, the ability to record all of the information automatically, and the ability to decrease subjective factor (influence of the observer). Nevertheless, using technical equipment for measuring behavior and brain functions in subjects with a mental handicap can entail great difficulties. For example, electrophysiology (EEG) and neuroradiology (tomography and magnetic resonance imaging) - the methodologies generally employed in clinic and research laboratoriesare complicated in practice and stressful for subjects. These methodological approaches can create a number of problems, especially in the work with patients who can exhibit extraordinary reactions to changes in their surroundings - for example, people with autism (Gurney et al., 2003). It therefore appears necessary to develop technological instruments that fulfill the aforementioned traditional requirements, as well as additional requirements aimed at facilitating experimental procedures (relative ease of use, creating interest and motivation in subjects, transportability, scalability, lower cost).

A device for measuring signal transfer within one brain hemisphere and between hemispheres-called Sensopress - has been developed at the Center for Neuropsychological Research at the University of Trier, Germany, by R. A. Wittling (Wittling \& Wittling, 2005). This instrument was designed for measuring brain asymmetry in healthy adult people and was used in academic researches at the Center. It consists of two small (both in size and weight) identical panels with buttons for the fingers of each hand and a laptop computer with special software controlling the device, and it can be easily transported to the patient if necessary. The measuring procedure is not stressful because during the experiment, the subject sits at the table with nothing restricting his or her movements (belts, supports, etc.), and there are also no electrodes or other equipment placed on his or her skin. The only places for contacts between the subject and the device are the buttons for fingers that realize the stimulation and mea-

E. Schweiger, schweiger@znf.uni-trier.de 
sure the response. As such, the instrument seems to answer both traditional and additional requirements.

The device for measuring brain asymmetry was employed because, for the last three decades, a body of publications has shown that the pattern of brain asymmetry in people with mental handicaps - including autism, depression, and schizophrenia - differs from that of normal subjects (Bench, Frackowiak, \& Dolan, 1995; Bruder, 2003; Dollfus et al., 2005; Herbert et al., 2005; Plailly, d'Amato, Saoud, \& Royet, 2006). It has also been confirmed that the pattern of brain asymmetry can be deliberately changed. Each brain hemisphere can be selectively activated by training behavioral and sensory asymmetries, and the changes can be of a short-term or chronic character (Rizhova, Vershinina, Balashov, Kulagin, \& Kokorina, 2006; Wittling, 1995). These facts strengthen the importance of investigating brain asymmetry in people with a mental handicap in order to develop better diagnostic and therapeutic methods.

Children with autism were chosen to participate in our experiments for several reasons. Autism is a serious, lifelong developmental disorder characterized by impairments in social function, speech and language deficits, and unusual behavioral manifestations, such as repetitive movements. The degree of impairment extends from mild autism to severe handicap (Rutter, 2003). Seventy-five percent of individuals with autism have mental retardation (Cody, Pelphrey, \& Piven, 2002). Numerous publications have reported on the rise in the prevalence of autism in various countries, such as the USA and Great Britain, during the two last decades (Newschaffer \& Curran, 2003; Williams, Higgins, \& Brayne, 2006; Wong \& Hui, 2008; Yeargin-Allsopp et al., 2003). Blaxill (2004) established in his review that this increase cannot be explained by improvements in diagnostic procedures and case ascertainment, and that it must have objective causes. Autism is becoming a public health problem. The disorder has complicated variable pathophysiological mechanisms in the brain, and we are still a long way from understanding its neurobiology. To date, no single region of the brain or pathophysiological mechanism has been found to be associated with all cases of autism (Santangelo \& Tsatsanis, 2005). These facts explain the growing interest of researchers in the neuropathology of autism.

Numerous publications have shown that brain asymmetry in people with autism is changed in comparison with that of normal subjects, involving structural and functional deficiency in the left cerebral hemisphere. For example, the lateral brain ventricle was found to be enlarged on the left side in autistic subjects (Hauser, DeLong, \& Rosman, 1975). EEG activity was reduced in the left hemisphere in autistic individuals (Dawson, Warrenburg, \& Fuller, 1982, 1983). Regional cerebral blood flow (an indicator of functional activity) was greater in the right hemisphere than in the left hemisphere in autistic subjects, whereas the reverse pattern was seen in control subjects. These results have been reported both for global cerebral perfusion (Burroni et al., 2008) and for different cortical areas, such as the sensorimotor and parieto-temporal cortices (Boddaert et al., 2003; Chiron et al., 1995; Wilcox, Tsuang, Ledger, Algeo, \& Schnurr, 2002) and prefrontal cortex
(Ohnishi et al., 2000; Pinkham, Hopfinger, Pelphrey, Piven, \& Penn, 2008). These facts show the importance of further investigating brain asymmetry in people with autism. Such studies can broaden our understanding of the underlying mechanisms of this disorder.

The aim of our present study was to measure brain asymmetry in autistic children with Sensopress. We wanted to verify whether this device is suitable for the experiments with autistic children, how they can react to the procedure, whether the method is sensitive enough to measure brain asymmetry in these children, and whether the results are comparable with those of studies in which other methods were used to investigate brain asymmetry in people with autism.

\section{METHOD}

\section{Participants}

Two groups of participants were tested. The autistic spectrum disorders (ASD) group consisted of boys who were 7-18 years of age (average age $13.79 \pm 0.55, N=34$ ), who had the diagnosis of autism by Danish child psychiatrists, and who attended a special Danish school for autistic children (the West Zealand Autism Center [Autisme Center Vestsjelland]). Boys with both normal intellect and a degree of developmental delay were included in the ASD group in the ratio $1: 1$. The control group $(N=34)$ consisted of normal boys matched with the autistic subjects in age, who attended normal public schools. All control children passed a social communication questionnaire (SCQ) test (Rutter, Baily, \& Lord, 2003) to verify that none showed symptoms of autism.

\section{The Instrument}

The device contains two identical panels that are $23 \times 18 \times$ $4.7 \mathrm{~cm}$ in size, with 18 -mm-wide buttons for the fingers of each hand. The buttons have two functions. They can apply a slight tactile stimulation to a finger, and they can be depressed by the finger to provide a motor response to tactile stimulation, allowing measurement of the response time. There is a small 5-mm-wide hole in the middle of each button. A smooth metal rod that can lightly touch the finger through the hole performs the tactile stimulation. All parts of the device can be easily placed on a normal working table. The total weight of the device and the accompanying notebook computer is $6,900 \mathrm{~g}$. Therefore, the device together with the notebook can be easily transported and prepared for use in about $15 \mathrm{~min}$. During the period of our experiments, the device was placed in an isolated room at the school for children with autism in the West Zealand Autism Center in Denmark.

The device is controlled by special software. It is possible to set the duration and intensity of the tactile stimulus (from 20 to $999 \mathrm{msec}$ ), the time interval between successive stimuli and their sequences, and the number of stimulations in one test. The test parameters are set up before the experiment and stored in the software. The test procedure is performed and recorded automatically, and the operator is unable to change the test parameters or the records during testing. A few of the standard methods implemented in the device software were used for the purposes of the present experiment.

\section{Test Procedures}

\section{Finger-Tapping (FT) Test}

The subject was asked to repeatedly press a button on the panel as quickly as possible for $10 \mathrm{sec}$ using the index finger of one hand. After a break of $5 \mathrm{sec}$, the same procedure was performed using the index finger of the other hand. This procedure was repeated 12 times. The device recorded the mean number of finger taps for each hand during each 10 -sec period. The average time for one finger tap, $t$, was calcu- 
lated for the left and right index fingers (as a measure of manual motor speed) as $t=10 \cdot 12 / N$, where $N$ is the total number of finger taps.

\section{Tactile Reaction Time (TRT) Test}

This test allows the rate of tactile processing within one hemisphere and interhemispheric transfer to be measured. The subject is asked to focus attention on the index fingers and to keep them on the buttons. As soon as tactile stimulation is applied to one finger, the subject must respond by pressing the button using a given finger. All of the subjects were given the same test using the following standard parameters: (1) The duration of the tactile stimulation was $30 \mathrm{msec}$; (2) the interval between successive stimuli changed in random order from 2,000 to $3,000 \mathrm{msec}$; and (3) the sequence of stimuli sent to the right or left hand was random. All of the reactions of the subjects were recorded. The records included the following information about each finger tap: (1) the finger the tactile signal was sent to, (2) the finger that was supposed to respond, (3) the finger that actually responded, and (4) the reaction time (the time elapsed between the end of the tactile stimulus and the moment a finger tap was detected)

The tests consisted of four sessions involving 60 stimulations each, with a break in-between. Each session was 3 min in duration. The length of the break depended on the participant. The next session started when the child said he was ready to continue. The tactile stimulation was performed using a single signal applied in a random order to either the left or the right finger in all of the sessions. In the first session, the participant was asked to respond to the stimulation by pressing the button with the right finger only, no matter which finger the stimulation was applied to. In the second session, he was asked to respond to all signals using the left finger only. The third and fourth sessions were similar to the first two. Wrong reactions were excluded from the samples. Since the right and left index fingers have different manual motor speeds, the time for one finger tap, $t$, using the given finger (determined during the FT test) was divided in two and subtracted from the response time. The time, $t$, was divided in two because the finger makes two rhythmic movements (up and down) during the FT test, within time $t$. In the TRT test, the reaction time includes only the down movement.

\section{Evaluation of Unilateral and}

\section{Bilateral Processing of Tactile Stimulation}

Unilateral processing. The rate of tactile processing within one hemisphere can be evaluated when the tactile stimulation and response are performed on the same side. The response time for the left-sided condition $(\mathrm{L} / \mathrm{L})$ indicates the rate of right hemispheric processing, whereas the response time for the right-sided condition $(\mathrm{R} / \mathrm{R})$ indicates the rate of left hemispheric processing.

Bilateral processing. Bilateral processing of tactile stimulation can be evaluated when the stimulation is applied to one hand, but the other hand performs the response $(\mathrm{R} / \mathrm{L}$ and $\mathrm{L} / \mathrm{R})$. This procedure is able to measure interhemispheric transfer time by calculating the difference in the response time between the unilateral condition and the bilateral condition. For example, the difference in the response time between the $\mathrm{R} / \mathrm{L}$ and $\mathrm{L} / \mathrm{L}$ conditions indicates the interhemispheric transfer time from the left to the right hemisphere. Correspondingly, the difference in the response time between the L/R and $\mathrm{R} / \mathrm{R}$ conditions indicates the interhemispheric transfer time from the right to the left hemisphere.

\section{Experimental Protocol}

At the beginning of the test, each subject was given brief oral information about the device, and was then allowed to exercise using the buttons for a few minutes. The testing started with the FT test, followed by the TRT test. The whole procedure took about $30 \mathrm{~min}$.

\section{Statistical Analysis}

Mixed ANOVAs were used to assess asymmetry within and between the groups. Comparisons between groups were also made using $t$ tests and Mann-Whitney tests. Paired $t$ tests and Wilcoxon signed ranks tests were used to compare the reaction time on the left and right sides within the groups. The $\chi^{2}$ test was used to compare the distributions.

The experiments were performed with the permission of The Danish National Committee on Biomedical Research Ethics.

\section{RESULTS}

Both autistic and normal children responded positively to the test procedure and liked to participate in the experiments. They accepted the testing as a kind of game.

In our experiments, the functions of brain hemispheres and their interaction was evaluated by measuring simple reflexes on the right and left sides of the body. Reaction times of the left and right fingers were measured. Then the pure muscle response (the finger tap) was used to measure the rate of tactile reactions for each hemisphere. It is well known that motor functions of right and left hands are not equivalent for most human beings (Annet, 2002). We therefore investigated how quickly the right and left index fingers performed finger taps in each individual participant. The results have shown that the autistic children functioned significantly slower in the FT test with both right and left index fingers as compared with the controls, and the right index finger tapped quicker than did the left finger in most autistic and control children (mixed ANOVA, $p<.000$, Figure 1A).

The distribution of children who functioned quicker with the right, the left, or the right and left fingers equally quickly was similar in the ASD and control group. In the ASD group, there were only 2 boys who tapped quicker with their left fingers than with their right, and 3 boys who tapped equally with both fingers. In the control group, there were 3 boys who tapped quicker with their left fingers than with their right, and 1 boy who tapped equally with both fingers.

To evaluate the degree of population asymmetry in both groups, we calculated the difference between manual motor speed of the right and left fingers in each subject; then, we compared the mean of difference with 0 for each sample and compared the samples. As is seen in Figure 1C, the mean of difference constituted $-23.25 \mathrm{msec}$ in the autistic children and $-18.83 \mathrm{msec}$ in the control children, and it significantly differed from $0(p<.001)$, but there was no difference between the autistic and control children.

These data together showed that although the autistic children tapped significantly slower than did the control children with both the left and right fingers, the ratio of manual motor speed on the left and right sides was similar in both groups. This means that autistic and control children did not differ in the profile of manual asymmetry.

Because of the significant advantage of the right finger in motor function, the following correction was made: The average time of the tap performed by right or left finger, which was determined in the FT test and divided by 2, was deducted from the reaction time where the corresponding finger responded to the stimulation.

Similar to what we saw in the FT test, children with autism functioned slower than did the controls in the TRT test. The reaction time was, in general, longer in autistic children than in the control children, independently on the side of reaction, and it was found for both unilateral and bilateral processing of tactile stimulation (mixed or 

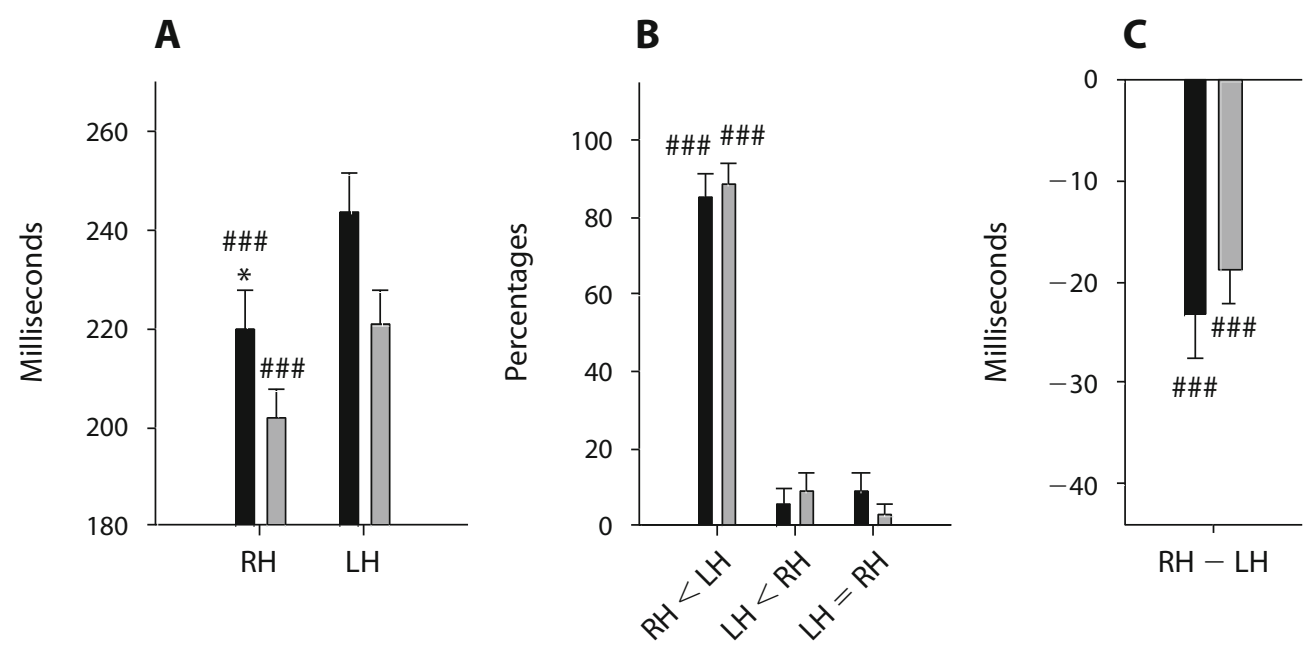

Figure 1. (A) Manual motor speed of the right (RH) and left (LH) index fingers in autistic and control children in the finger-tapping test. Data are given as means $\pm S E M$ s. Thirty-four autistic and control children participated. Black bars, autistic children; gray bars, control children. " $p<.05$ when compared with motor speed of the right finger in control children. \# $p<.001$ when compared with motor speed of the left finger inside the group. (B) The number of children (in percentages) with the right finger faster $(\mathrm{RH}<\mathrm{LH})$, the left finger faster $(\mathrm{LH}<\mathrm{RH})$, and with equal dexterity $(\mathbf{L H}=\mathbf{R H})$ in autistic and control children in the finger-tapping test. Data are given as means $\pm S E M s$. \#\# $p<.001$ when compared with the children who have the left finger faster in the same group. (C) The mean of difference in manual motor speed of the right and left fingers in the autistic and control children. Data are given as means \pm SEMs. \#p $<.001$ when compared with 0.

repeated measures ANOVAs, $p<.000)$. However, in this test, the groups differed in the factor asymmetry $(p<.05)$, meaning that children with autism had changed profiles of brain asymmetry as compared with the controls.

\section{Unilateral Processing of Tactile Stimulation}

To elucidate whether the right or left hemisphere had an advantage in tactile processing, we compared $\mathrm{L} / \mathrm{L}$ time and $\mathrm{R} / \mathrm{R}$ time in each group and between each group.

$\mathrm{L} / \mathrm{L}$ time (which indicates the rate of tactile processing within the right hemisphere) was shorter than $\mathrm{R} / \mathrm{R}$ time (which indicates the rate of tactile processing within the left hemisphere) in $82.4 \%$ of the autistic boys and in $41.2 \%$ of the controls ( $\chi^{2}$ test, $\left.p=.001\right)$. $\mathrm{R} / \mathrm{R}$ time was shorter than $\mathrm{L} / \mathrm{L}$ time in $14.7 \%$ and $50 \%$ of the children in the ASD and control groups, respectively ( $\chi^{2}$ test, $\left.p<.01\right)$. The children with equivalent performance on the left and right sides constituted $2.9 \%$ in the ASD group and $8.8 \%$ in the control group ( $\chi^{2}$ test, $p>.05$ ) (see Figure 2). The data showed that the distribution of children with different individual asymmetry in the ASD and control groups was significantly different.

To evaluate the degree of population asymmetry in the autistic and control children, we calculated the difference of $\mathrm{R} / \mathrm{R}-\mathrm{L} / \mathrm{L}$ in each individual subject and then compared the mean of difference with 0 . As is shown in Figure 3, the mean of difference constituted $29.60 \mathrm{msec}$ in the autistic children and differed significantly from $0(p<.000)$. This result confirmed population brain asymmetry: The rate of tactile processing within the right hemisphere was higher than that within the left hemisphere in the ASD group. The mean of difference of $\mathrm{R} / \mathrm{R}-\mathrm{L} / \mathrm{L}$ in the control children did not dif-

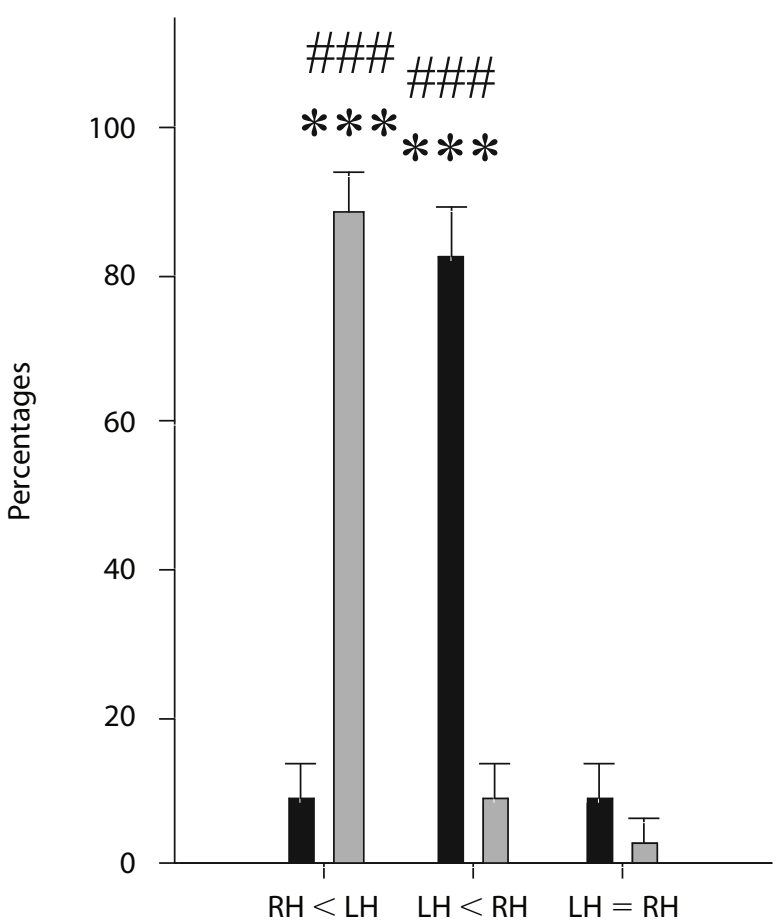

Figure 2. The number of children with the reaction time shorter on the right $(R / R<L / L)$ or the left $(L / L<R / R)$ side and equal performance on both sides $(L / L=R / R)$ in autistic and control children in the tactile reaction time test. Data are given as means $\pm S E M$. Black bars, autistic children; gray bars, control children. ${ }^{* * *} p<.001$ when autistic and control children were compared. $\#$ $\#$ $<.001$ when compared with the reaction time on the other side of the body in the same group of children. 


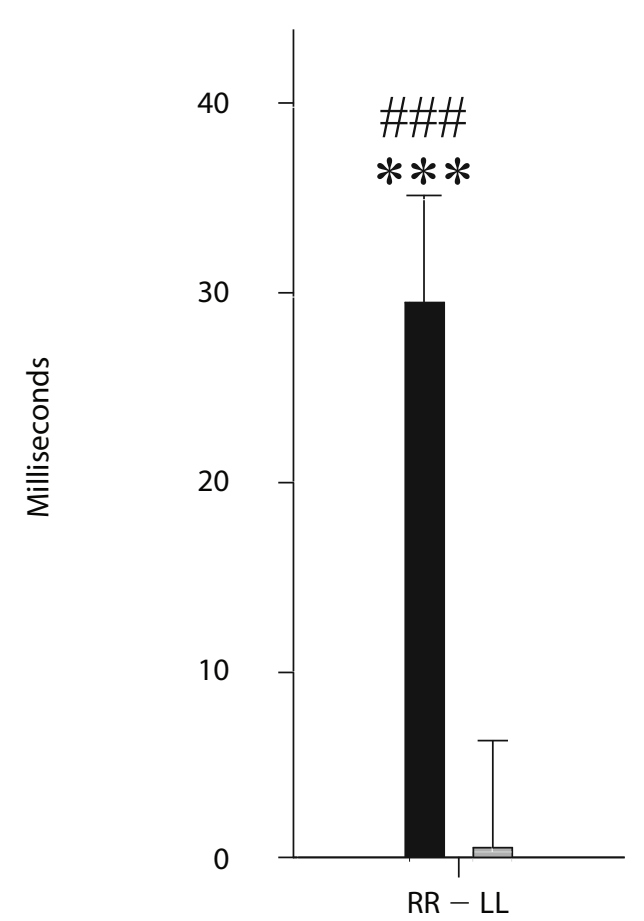

Figure 3. The mean of difference in the reaction time on the right and left sides in the autistic and control children in the tactile reaction time test. Data are given as means $\pm S E M$ s. Black bars, autistic children; gray bars, control children. ${ }^{* * *} p<.001$ when compared with the control. \#\#” $\quad$ \#.001 when compared with 0 .

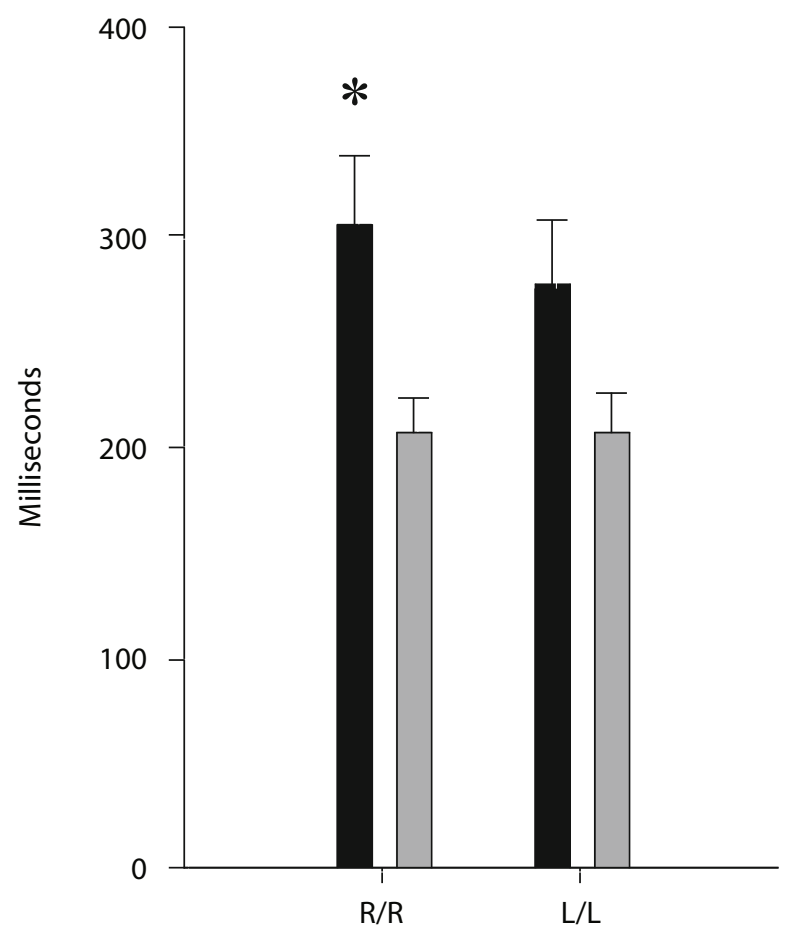

Figure 4. The reaction time on the right and left sides in the autistic and control children in the tactile reaction time test. Data are given as means $\pm S E M$ s. Black bars, autistic children; gray bars, control children. ${ }^{*} p<.05$ when compared with the control. fer from $0(0.53 \mathrm{msec})$, and it was significantly lower than in autistic children (independent samples test, $p<.001$ ).

The $R / R$ reaction time was significantly longer in autistic children than in the controls $(306.462 \pm 32.095 \mathrm{msec}$ as compared with $208.188 \pm 16.089 \mathrm{msec}$, respectively, $p<.05$ ), whereas there was a tendency for the $\mathrm{L} / \mathrm{L}$ reaction time to be longer in autistic children than in the controls $(276.86 \pm 31.88 \mathrm{msec}$ and $207.65 \pm 17.77 \mathrm{msec}$, respectively, $p=.62$ ) (see Figure 4 ). It means that the delay in the rate of tactile processing in the brain hemispheres in autistic children was more pronounced in the left than in the right hemisphere.

The present data indicate that the children with autism had population brain asymmetry in the rate of tactile processing: The right hemisphere functioned quicker than did the left hemisphere. The control children had no population asymmetry in this case. The results confirm that the brains in autistic boys were more asymmetrical than were those in the control children.

\section{Bilateral Processing of Tactile Stimulation}

The time of transfer from the right to the left hemisphere was calculated as the difference between the L/R and R/R reaction times, and from the left to the right hemispheres as the difference between the $\mathrm{R} / \mathrm{L}$ and $\mathrm{L} / \mathrm{L}$ reaction times. As is shown in Figure 5, interhemisphere transfer had a similar rate in both directions in the control children, whereas the transfer from the right to left hemisphere was significantly quicker than in the opposite direction in the autistic children.

These results indicate that children with autism rather than control children had asymmetrical bilateral processing of tactile stimulation with the superiority of the right hemisphere. Thus, the present results indicate that the autistic children had more pronounced brain asymmetry in tactile processing than did the controls. The right hemisphere functioned quicker than the left hemisphere.

\section{DISCUSSION}

We used a new device in our research that was able to precisely measure the reaction time between a tactile stimulus applied to the index finger of either the right or left hand, and the response to the stimulation - a tap performed by a predetermined finger. If the same finger is used for both the stimulation and response to the tactile signal, then the tactile processing takes place within one brain hemisphere unilaterally, and the reaction time reflects the rate of this process. Interhemisphere transfer takes place if the stimulus is sent to one index finger, but the finger of the other hand has to respond. This has been confirmed in a number of experiments in which an EEG and an fMRI were used for directly measuring brain activity (Barnett, Corballis, \& Kirk, 2005; Kicic, Lioumis, Ilmoniemi, \& Nikulin, 2008). The reaction time in the present case indicates the speed of signal transfer between brain hemispheres. The estimation of interhemisphere transfer time as a difference between the reaction time measured in bilateral and unilateral conditions is widely accepted (Mooshagian, Iacoboni, \& Zaidel, 2008; Shelton \& Knight, 1984; Tassinari, Aglioti, 


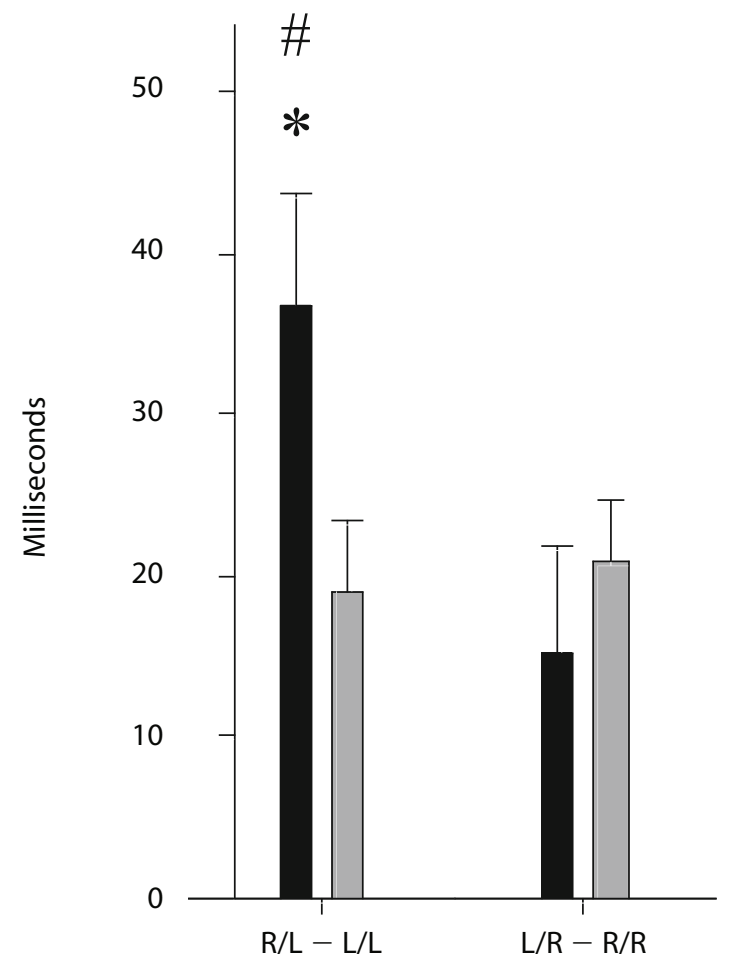

Figure 5. The rate of interhemisphere signal transfer in autistic and control children in the tactile reaction time test. $R / L-L / L$, signal transfer from the left to right brain hemisphere; $L / R-R / R$, signal transfer from right to left brain hemisphere. Data are given as means $\pm S E M s$. Black bars, autistic children; gray bars, control children. ${ }^{*} p<.05$ when compared with control. ${ }^{\#} p<.05$ when compared with $L / R-R / R$ in the same group.

Pallini, Berlucchi, \& Rossi, 1994). Therefore, the method that we used allowed us to measure the speed of unilateral and bilateral tactile processing in the brain.

The aim of our present study was to use this method to measure brain asymmetry in children with a mental disability-autism spectrum disorder - and to compare the results with studies in which other methods were used to investigate brain asymmetry in people with autism.

The main advantage of our method over others that are traditionally used to research brain asymmetry was its practical simplicity and its ability to motivate participants. The device was easily transported to the school for autistic children. The children participating in the experiments accepted the test procedure as a kind of game and enjoyed "playing with the buttons."

Two of the present study's findings seem to be of particular importance for assessing the experimental method: The reaction time to the tactile stimulation was generally longer in the autistic children than in the control children, and pronounced asymmetry was found in the autistic children when we compared the reaction time with tactile stimulation on the right and left sides of the body. In contrast, the control children had similar reaction times for both sides.

The first finding is in agreement with numerous reports presenting evidence of delay in physical development and reduced functional brain activity in autistic children. For example, fMRI studies have shown that one of the most common brain abnormalities found in autistic children is brain enlargement, with a disproportional increase in white matter and cerebrospinal fluid, and a decrease in gray matter (Herbert, 2005; McAlonan et al., 2005). Studies using the single positron emission computerized tomogram (SPECT) method have found that the cerebral blood flow was reduced in autistic children throughout the whole brain and in such regions as the prefrontal and temporo-parietal cortices (Burroni et al., 2008; Wilcox et al., 2002). In summarizing the available electrophysiological findings for autism, McCann (1981) confirmed that autistic children are generally less responsive to sensory stimulation.

The reaction time included the time for tactile processing in the brain, as well as the time for finger movement. The reaction time was significantly shorter for the autistic children when the stimulation and response were performed on the left side, as opposed to on the right side. A number of publications have shown that autistic children have a shift from right-handedness that is seen in the general population (Dane \& Balci, 2007; Gillberg, 1983; Soper et al., 1986). We therefore investigated whether the reaction time asymmetry was due to either the difference in motor function of the right and left fingers, or the asymmetry in tactile processing in the two brain hemispheres. The results in the FT test showed that the right finger functioned significantly faster than the left finger, in both autistic and control children. This fact seems to be in contradiction with the reports in the literature. The methods employed for measuring handedness in autistic children in the aforementioned studies were different and did not include a finger-tapping test. The children with autism participating in the present experiments used to spend a few hours every day using a computer and exercised their right index fingers by clicking the mouse. This could explain the observed manual asymmetry. Nevertheless, right-finger superiority cannot account for the faster left-side reaction time. The calculated average time for one finger tap was subtracted from the response time for the given finger when assessing the reaction time. Moreover, the autistic and control children did not differ in terms of manual asymmetry, but had significantly different reaction-time asymmetry. These facts allow us to conclude with confidence that measuring the $\mathrm{L} / \mathrm{L}$ and $\mathrm{R} / \mathrm{R}$ reaction times using the Sensopress device permitted the speed of unilateral tactile processing in the right and left brain hemispheres to be assessed.

The results of our present experiments have shown that the autistic children exhibited population asymmetry, expressed in the faster tactile processing speed in the right hemisphere than in the left. This fact is in agreement with numerous reports in the literature indicating general or localized left-hemisphere dysfunction in subjects with autism. For example, ventricular enlargement asymmetry found in the brain in a group of autistic children resulted in brain-matter deficiency in the left hemisphere (Hauser et al., 1975). Cerebral blood flow was reduced in the entire left hemisphere, and regionally, in comparison with that in the right hemisphere (Chiron et al., 1995), and glucose metabolism was reduced in the left posterior putamen (Siegel et al.,1992) in autistic subjects. The majority of 
studies indicate dysfunction in the temporoparietal and temporo-occipital areas involved in speech processing (Boddaert et al., 2004; Herbert et al., 2002; Meresse et al., 2005). However, there are also contradictory findings indicating bilateral brain dysfunction in the temporal and parietal area in autistic subjects (Courchesne, Press, \& Yeung-Courchesne, 1993; Zilbovicius et al., 2000).

The brain asymmetry for unilateral tactile processing that we observed in the autistic children was not seen in the control children. Studies examining the degree of brain asymmetry in autistic subjects as compared with that in normally functioning individuals are contradictory and cannot easily be compared because different methods were used and different brain functions were investigated. For example, asymmetry indices for the synthesis of serotonin in the frontal cortex, thalamus, and dentate nucleus were higher in autistic boys than in controls (Chugani et al., 1997). Hemispheric lateralization observed using an EEG was significant in control children, whereas no lateralization was observed in children with autism (Ogawa et al., 1982).

The population asymmetry in the interhemisphere transfer was found in the autistic children. The signals transferred significantly quicker from the right to the left hemisphere than they did in the opposite direction. This asymmetry was not seen in the group of control children. For the last few years, a number of publications have indicated that an important feature of the autism pathophysiology might be deficient in anatomical and functional connections in the brain. Thus, it has been found that the main comissure connecting two brain hemispheres - corpus callosum-was smaller in both highly functioning and mentally retarded autistic participants than it was in control participants (Berthier, 1994; Cody et al., 2002; Hughes, 2007; Steiner, Guerreiro, \& Marques-de-Faria, 2004; Vidal et al., 2006). fMRI studies found a deficit in unilateral and bilateral functional connectivity in the highly functioning autistic patients when they were performing a cognitive task (Just, Cherkassky, Keller, Kana, \& Minshew, 2007). The time for interhemisphere transfer was significantly longer in the autistic children than in the control children only in one direction - from the left to the right hemisphere-but the transfer from the right to the left hemisphere even tended to be quicker than that in the control. The interactions between the hemispheres can be dominated completely by one of them (Banich, 1995), but we could not find in the available literature indications for asymmetry in interhemisphere transfer in subjects with autism. This lack of information can be explained by the fact that corpus callosum has segmental structure, and the channels for information of different modality are separated (Banich, 1995). The researchers focused mainly on the parts that were decreased in size in corpus callosum, which connect symmetrical areas of the cortex involved in speech and face processing and other cognitive functions (Just et al., 2007, Minshew \& Williams, 2007).

Brain asymmetry phenomena have been intensively studied for about 150 years, and we now have an enormous body of information about the specialization and collaboration of the two brain hemispheres as they regu- late the various activities of the body. Most of this research has had a predominantly theoretical nature, but the fact that brain asymmetry mechanisms are involved in the pathology of mental disabilities - including autism - is beyond doubt, and an assessment of brain asymmetry could be used in the diagnosis of mental illness. We believe that an important problem preventing observations from academic science flowing into practice in this case has been the complexity and high cost of the methods for measuring brain asymmetry. As such, the method that we used has an advantage over other methods traditionally used to research brain asymmetry. It permits brain asymmetry to be measured using a test procedure that is simple to use for both researchers and participants. It can be easily transported and set up in an ordinary room, and does not require special research laboratory facilities. We therefore believe that our present method can be used in the future to measure brain asymmetry when diagnosing autism and other mental abnormalities in children and adults.

\section{AUTHOR NOTE}

Address correspondence to E. Schweiger, Center for Neuropsychological Research, University of Trier, Johaniterufer 15, Trier D-54290, Germany (e-mail: schweiger@znf.uni-trier.de).

\section{REFERENCES}

Akshoomoff, N., Corsello, C., \& Schmidt, H. (2006). The role of autism diagnostic observation schedule in the assessment of autism spectrum disorders in school and community settings. California School Psychologist, 11, 7-19.

Annett, M. (2002). The puzzle of handedness and cerebral speech. In M. Annett (Ed.), Handedness and brain asymmetry: The right shift theory (pp. 3-20). New York: Taylor \& Francis.

BANICH, M. T. (1995). Interhemispheric processing: Theoretical considerations and empirical approaches. In R. J. Davidson \& K. Hugdahl (Eds.), Brain asymmetry (pp. 427-450). Cambridge, MA: MIT Press.

Barnett, K. J., Corballis, M. C., \& KirK, I. J. (2005). Symmetry of callosal information transfer in schizophrenia: A preliminary study. Schizophrenia Research, 74, 171-178.

Bench, C. J., Frackowiak, R. S. J., \& Dolan, R. J. (1995). Changes in regional cerebral blood flow on recovery from depression. Psychological Medicine, 25, 247-251.

Berthier, M. L. (1994). Corticocallosal anomalies in Asperger's syndrome. American Journal of Roentgenology, 162, 236-237.

BlAXILL, M. F. (2004). What's going on? The question of time trends in autism. Public Health Reports, 119, 536-551.

Boddaert, N., Belin, P., Chabane, N., Poline, J.-B., Barthelemy, C., Mouren-Simeoni, M. C., ET AL. (2003). Perception of complex sounds: Abnormal pattern of cortical activation in autism. American Journal of Psychiatry, 160, 2057-2060.

Boddaert, N., Chabane, N., Belin, P., Bourgeois, M., Royer, V., Barthelemy, C., ET AL. (2004). Perception of complex sounds in autism: Abnormal auditory cortical processing in children. American Journal of Psychiatry, 161, 2117-2120.

Bruder, G. E. (2003). Frontal and parietotemporal asymmetries in depressive disorders: Behavioral, electrophysiologic, and neuroimaging findings. In K. Hugdahl \& R. J. Davidson (Eds.), The asymmetrical brain (pp. 719-742). Cambridge, MA: MIT Press.

Burroni, L., Orsi, A., Monti, L., Hayek, Y., Rocchi, R., \& Vattimo, A. G. (2008). Regional cerebral blood flow in childhood autism: A SPET study with SPM evaluation. Nuclear Medicine Communications, 29, 150-156.

Chiron, C., Leboyer, M., Leon, F., Jambaque, I., Nuttin, C., \& Syrota, A. (1995). SPECT of the brain in childhood autism: Evidence for a lack of normal hemispheric asymmetry. Developmental Medicine \& Child Neurology, 37, 849-860.

Chugani, D. C., Muzik, O., Rothermel, R., Behen, M., Chakra- 
BORTY, P., MANGNER, T., ET AL. (1997). Altered serotonin synthesis in the dentatothalamocortical pathway in autistic boys. Annals of Neurology, 42, 666-669.

Cody, H., Pelphrey, K., \& Piven, J. (2002). Structural and functional magnetic resonance imaging of autism. International Journal of Developmental Neuroscience, 20, 421-438.

Courchesne, E., Press, G. A., \& Yeung-Courchesne, R. (1993). Parietal lobe abnormalities detected with MR in patients with infantile autism. American Journal of Roentgenology, 160, 387-393.

Dane, S., \& Balci, N. (2007). Handedness, eyeness and nasal cycle in children with autism. International Journal of Developmental Neuroscience, 25, 223-226.

Dawson, G., Warrenburg, S., \& Fuller, P. (1982). Cerebral lateralization in individuals diagnosed as autistic in early childhood. Brain \& Language, 15, 353-368.

Dawson, G., WarRenburG, S., \& Fuller, P. (1983). Hemisphere functioning and motor imitation in autistic persons. Brain \& Cognition, 2, 346-354

Dollfus, S., Razafimandimby, A., Delamillieure, P., Brazo, P., Joliot, M., Mazoyer, B., \& Tzourio-Mazoyer, N. (2005). Atypical hemispheric specialization for language in right-handed schizophrenia patients. Biological Psychiatry, 57, 1020-1028.

GILLBERG, C. (1983). Autistic children's hand preference: Results from an epidemiological study of infantile autism. Psychiatry Research, 10, $21-30$

Gurney, J. G., Fritz, M. S., Ness, K. K., Sievers, P., Newschaffer, C. J., \& Shapiro, E. G. (2003). Analysis of prevalence trends of autism spectrum disorder in Minnesota. Archives of Pediatrics \& Adolescent Medicine, 157, 622-627.

Hauser, S. L., DeLong, G. R., \& Rosman, N. P. (1975). Pneumografic findings in the infantile autism syndrome. A correlation with temporal lobe disease. Brain, 98, 667-688.

HERBERT, M. R. (2005). Large brains in autism: The challenge of pervasive abnormality. Neuroscientist, 11, 417-440.

Herbert, M. R., Harris, G. J., Adrien, K. T., Zeigler, D. A., MaKris, N., KENNEDY, D. N., ET AL. (2002). Abnormal asymmetry in language association cortex in autism. Annals of Neurology, 52, 588-596.

Herbert, M. R., Ziegler, D. A., Deutsch, C. K., O'Brien, L. M., Kennedy, D. N., FilipeK, P. A., ET AL. (2005). Brain asymmetries in autism and developmental language disorder: A nested whole-brain analysis. Brain, 128, 213-226.

Hughes, J. R. (2007). Autism: The first firm finding = underconnectivity? Epilepsy \& Behavior, 11, 20-24.

Just, M. A., Cherkassky, V. I., Keller, T. A., Kana, R. K., \& MinsHew, N. J. (2007). Functional and anatomical cortical underconnectivity in autism: Evidence from an fMRI study of an executive function task and corpus callosum morphometry. Cerebral Cortex, 17, 951-961.

Kicic, D., Lioumis, P., ILmoniemi, R. J., \& Nikulin, V. V. (2008). Bilateral changes in excitability of sensorimotor cortices during unilateral movement: Combined electroencephalographic and transcranial magnetic stimulation study. Neuroscience, 152, 1119-1129.

McAlonan, G. M., Cheung, V., Cheung, C., Suckling, J., Lam, G. Y., TAI, K. S., ET AL. (2005). Mapping the brain in autism. A voxelbased MRI study of volumetric differences and intercorrelations in autism. Brain, 128, 268-276.

MCCANN, B. (1981). Hemispheric asymmetries and early infantile autism. Journal of Autism \& Developmental Disorders, 11, 401-411.

Meresse, I. G.,Zilbovicius, M., Boddaert, N., Robel, L., Philippe, A., Sfaello, I., ET AL. (2005). Autism severity and temporal lobe functional abnormalities. Annals of Neurology, 58, 466-469.

Minshew, J., \& WiLliams, D. L. (2007). The new neurobiology of autism. Neurological Review, 64, 945-950.

Mooshagian, E., Iacoboni, M., \& Zaidel, E. (2008). The role of task history in simple reaction time to lateralized light flashes. Neuropsychologia, 46, 659-664.

Newschaffer, C. J., \& Curran, L. K. (2003). Autism: An emerging public health problem. Public Health Reports, 118, 393-399.

Ogawa, T., SugiYama, A., Ishiwa, S., Suzuki, M., Ishihara, T., \&
SATO, K. (1982). Ontogenetic development of EEG-asymmetry in early infantile autism. Brain \& Development, 4, 439-449.

Ohnishi, T., Matsuda, H., Hashimoto, T., Kunihiro, T., Nishikawa, T. U., \& SASAKI, M. (2000). Abnormal regional cerebral blood flow in childhood autism. Brain, 123, 1838-1844.

Pinkham, A. E., Hopfinger, J. B., Pelphrey, K. A., Piven, J., \& Penn, D. L. (2008). Neural bases for impaired social cognition in schizophrenia and autism spectrum disorders. Schizophrenia Research, 99, 164-175.

Plailly, J., D' Amato, T., Saoud, M., \& Royet, J. P. (2006). Left temporo-limbic and orbital dysfunction in schizophrenia during odor familiarity and hedonicity judgments. NeuroImage, 29, 302-313.

Rizhova, L. Y., Vershinina, E., Balashov, Y. G., Kulagin, D. A., \& KoKorina, E. P. (2006). Relation of behavioral asymmetry to the functions of hypothalamus-pituitary-adrenal and reproductive systems in vertebrates. In Y. Malashichev \& W. Deckel (Eds.), Behavioral and morphological asymmetries in vertebrates (pp. 160-176). Portland, OR: Book News.

RutTer, M. (2003). Introduction: Autism-The challenges ahead. In G. Bock \& J. Goode (Eds.), Autism: Neural basis and treatment possibilities (pp. 1-9). Chichester, U.K.: Wiley.

Rutter, M., BAILY, A., \& LoRD, C. (2003). Social communication questionnaire. Los Angeles: Western Psychological Services.

Santangelo, S. L., \& Tsatsanis, K. (2005). What is known about autism. American Journal of Pharmacogenomics, 5, 71-92.

Shelton, E. L., \& KNight, R. G. (1984). Inter-hemispheric transmission time in schizophrenics. British Journal of Clinical Psychology, 23, 227-228

Siegel, B. V. J., Asarnow, R., Tanguay, P., Call, J. D., Abel, L., Ho, A. ET AL. (1992). Regional cerebral glucose metabolism and attention in adults with a history of childhood autism. Journal of Neuropsychiatry \& Clinical Neurosciences, 4, 406-414.

Soper, H. V., SatZ, P., Orsini, D. L., Henry, R. R., Zvi, J. C., \& SChulMAN, M. (1986). Handedness patterns in autism suggest subtypes. Journal of Autism \& Developmental Disorders, 16, 155-167.

Steiner, C. E., Guerreiro, M. M., \& Marques-De-Faria, A. P. (2004). Brief report: Acrocallosal syndrome and autism. Journal of Autism \& Developmental Disorders, 34, 723-726.

Tassinari, G., Aglioti, S., Pallini, R., Berlucchi, G., \& Rossi, G. F. (1994). Interhemispheric integration of simple visuomotor responses in patients with partial callosal defects. Behavioural Brain Research, 64, 141-149.

Vidal, C. N., Nicolson, R., DeVito, T. J., Hayashi, K. M., Geaga, J. A., Drost, D. J., ET AL. (2006). Mapping corpus callosum deficit in autism: An index of aberrant cortical connectivity. Biological Psychiatry, 60, 218-225.

Wilcox, J., Tsuang, M. T., Ledger, E., Algeo, J., \& Schnurr, T. (2002). Brain perfusion in autism varies with age. Neuropsychobiology, 46, 13-16.

Williams, J. G., Higgins, J. P. T., \& Brayne, C. E. G. (2006). Systematic review of prevalence studies of autism spectrum disorders. Archives of Disease in Childhood, 91, 8-15.

WitTling, W. (1995). In R. J. Davidson \& K. Hugdahl (Eds.), Brain asymmetry (pp. 305-358). Cambridge, MA: MIT Press.

WitTling, W., \& WitTLing, A. R. (2005). Europäische patentschrift EP 1656885 B1.

WonG, V. C. N., \& HUI, S. L. H. (2008). Epidemiological study of autism spectrum disorder in China. Journal of Child Neurology, 23, 67-72.

Yeargin-Allsopp, M., Rice, C., Karapurkar, T., Doernberg, N., Boyle, C., \& Murphy, C. (2003). Prevalence of autism in a US Metropolitan area. Journal of the American Medical Association, 289, 49-55.

Zilbovicius, M., Boddaert, N., Belin, P., Poline, J.-B., Remy, P., Mangin, J. F., ET AL. (2000). Temporal lobe dysfunction in childhood autism: A PET study. American Journal of Psychiatry, 157, 1988-1993.

(Manuscript received November 16, 2008; revision accepted for publication February 13, 2009.) 